\title{
Facts about Wildlife Diseases: Raccoon-Borne Pathogens of Importance to Humans-Viruses and Bacteria $^{1}$
}

\author{
Caitlin Jarvis, Samantha M. Wisely, and Mathieu Basille²
}

Northern raccoons (Procyon lotor, Figure 1) can carry many diseases that present significant health hazards to both people and pets. Some of these diseases are asymptomatic, showing no signs of infection, and often do not affect raccoons, but can still be passed on and deadly to other animals, including humans. Because it is not possible to be certain if a wild animal is sick, it is safer to consider the animal a hazard and avoid it. Contact animal control or a wildlife rehabilitator if you suspect an animal is sick or behaving abnormally (contact details for Florida wildlife rehabilitators can be found on the Florida Fish and Wildlife Conservation Commission website). Sick wild animals can act tame and confused but should never be approached as if they are domesticated. They are still wild animals that will likely see you as a threat, and can act aggressively. Due to their successful adaptation to urban environments, it is common for raccoons to come into contact with humans. This document is part of a series addressing health hazards associated with raccoons and specifically describes the most important raccoon-borne viruses and bacteria. Information on other raccoon-borne parasites, as well as more details about the raccoon roundworm Baylisascaris procyonis, can be found in other documents of this series. The following viruses and bacteria are known to occur in raccoons and are a concern for people and/or pets: rabies, canine distemper, feline distemper/panleukopenia, canine parvovirus,
Salmonella, tularemia, Edwardsiella septicemia, and leptospirosis (See Table 1 for a summary and prevention).

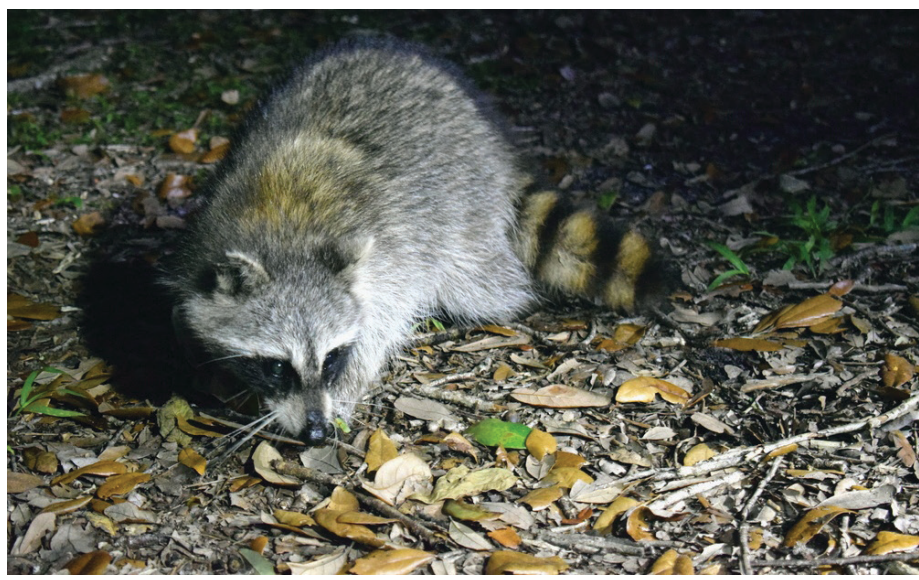

Figure 1. A young female raccoon in Broward County, south Florida. Credits: Mathieu Basille, UF/IFAS

\section{Viruses}

\section{Rabies}

Rabies is a ribonucleic acid (RNA) virus in the Rhabdoviridae family and one of the deadliest known diseases. If not treated early, rabies is nearly 100 percent fatal. About a dozen people in recorded history have contracted rabies and survived without prompt treatment of rabies and pre- or post-exposure vaccination. In contrast, over 59,000

1. This document is WEC433, one of a series of the Department of Wildlife Ecology and Conservation, UF/IFAS Extension. Original publication date October 2020. Visit the EDIS website at https://edis.ifas.ufl.edu for the currently supported version of this publication.

2. Caitlin Jarvis, former technician, UF/IFAS Fort Lauderdale Research and Education Center; Samantha M. Wisely, professor, Department of Wildlife Ecology and Conservation; and Mathieu Basille, assistant professor, Department of Wildlife Ecology and Conservation, UF/IFAS Fort Lauderdale Research and Education Center, Davie, FL 33314.

The Institute of Food and Agricultural Sciences (IFAS) is an Equal Opportunity Institution authorized to provide research, educational information and other services

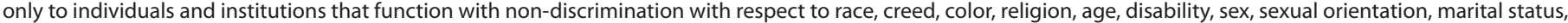

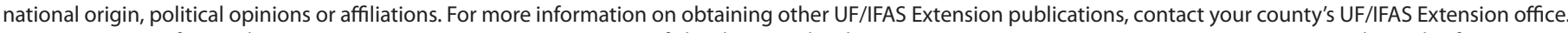
U.S. Department of Agriculture, UF/IFAS Extension Service, University of Florida, IFAS, Florida A \& M University Cooperative Extension Program, and Boards of County Commissioners Cooperating. Nick T. Place, dean for UF/IFAS Extension. 
die from rabies every year worldwide. Only 1 to 2 fatalities occur in the United States each year; however, thousands of people seek post-exposure treatment. Most deaths from rabies occur in Africa and Asia, where vaccination and treatment are not as readily available. Multiple organizations including the Centers for Disease Control and Prevention (CDC) and the World Health Organization (WHO) aim to end all human rabies deaths from canine rabies by 2030 through vaccination and education.

Rabies is transmitted in the saliva of infected mammals, including bats, raccoons, skunks, foxes, dogs, other canids, cats, and livestock. Theoretically, any mammal can be infected with rabies, although the above are the most reported. Worldwide, 99 percent of human cases are caused by unvaccinated dogs. In the United States, however, mandated vaccination of dogs has greatly reduced the number of cases in dogs and therefore the number of human exposures to rabies. Most human exposure (92.7 percent in 2018 ) in the United States comes from wildlife species (bats 33 percent, raccoons 30.3 percent, skunks 20.3 percent, and foxes 7.2 percent), and most human fatalities from rabies come from bats. In these cases, the victim did not know that bats were a rabies risk or did not realize they had been bitten. Current CDC data on rabies in the United States can be found on their website. The data show that while bats with rabies are found in every state except for Hawaii, rabies variants associated with medium-sized carnivores are geographically distinct in the United States (Figure 2). Raccoons in particular function as a reservoir for rabies throughout the southern and eastern United States. This does not mean that raccoons are the only species that may have rabies in the area; cross-species transmission of rabies virus variants (for example, infection of dogs with raccoon rabies variant) is possible. Fortunately, vaccination of pets and education have greatly reduced the number of rabies cases in humans and domestic animals in many areas of the world.

Rabies can cause aggressive behavior and excessive salivation; however, these are by no means the only symptoms. A rabid animal may also act tame, become active at unusual hours, or exhibit neurological abnormalities. Raccoons will occasionally forage for food during the day if it is quiet, so a daytime sighting of a raccoon is not cause for alarm on its own. If the raccoon shows no fear of humans or exhibits neurological abnormalities, however, it could be rabid. Either way, raccoons, like all wild animals, should be avoided.

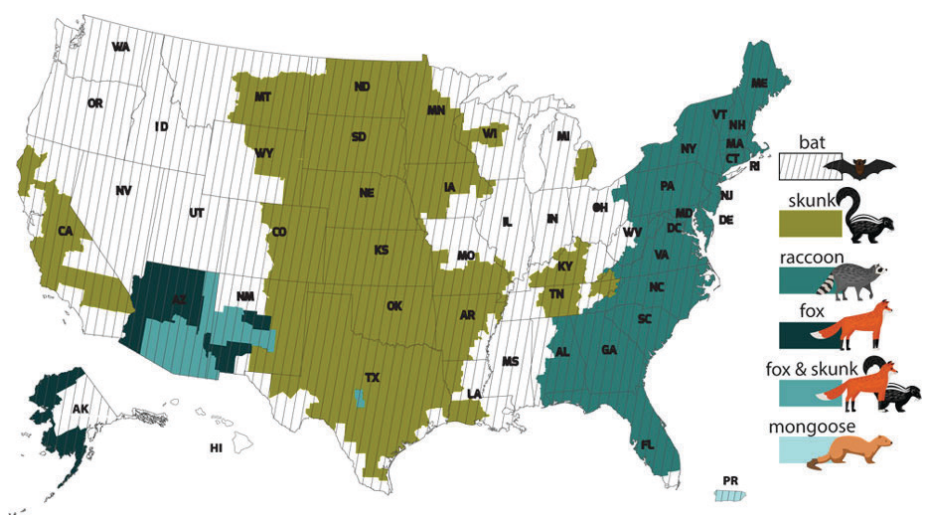

Figure 2. Rabies virus variants associated with bats and major medium-sized carnivore species in the United States. Credits: Centers for Disease Control and Prevention. https://www.cdc. gov/rabies/location/usa/surveillance/wild_animals.html

Rabies has been observed in every county in the state of Florida (Figure 3, Table 2). The Florida Department of Health publishes yearly records of reported cases that can be found on the Florida Department of Health website. In 2017, 78 cases of rabies were reported in wildlife, 36 of which were from raccoons.

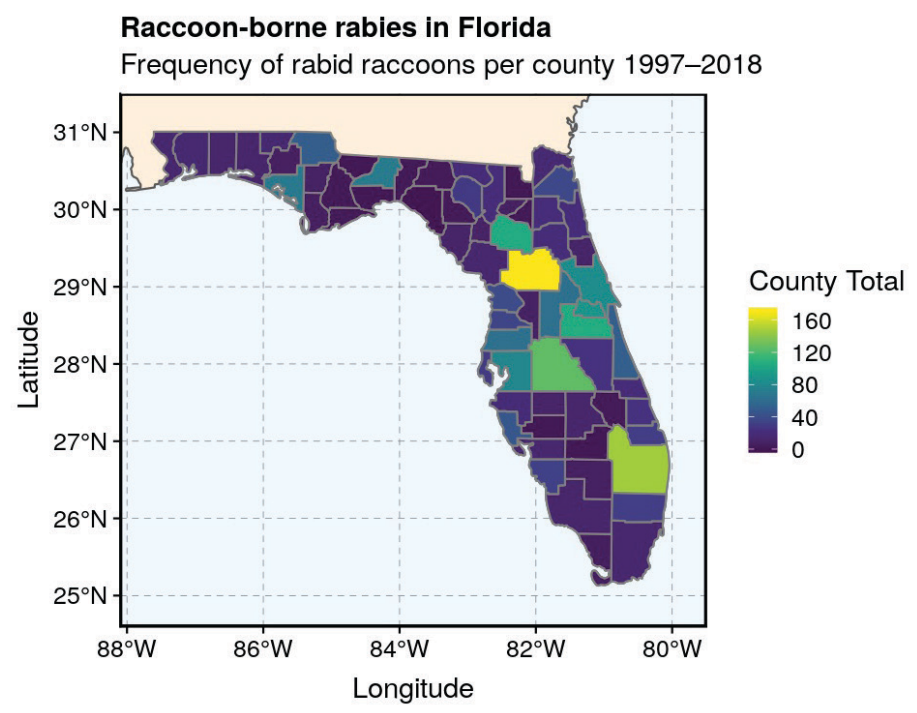

Figure 3. Raccoon-borne rabies cases in Florida by county (19972018). Taylor County is the only county in Florida to have zero cases of raccoon-borne rabies since 1997. Marion County has the most cases at 171.

\section{PRE-EXPOSURE VACCINATION}

Rabies pre-exposure vaccination is available for humans, but even if the pre-exposure vaccination is administered, it is still imperative to seek immediate post-exposure treatment if exposed to a potentially rabid animal. Due to the high cost (pre-exposure vaccination can cost in excess of $\$ 1,000$ in the United States), prophylactic treatment is recommended only for people who are more likely to come into contact with rabid animals, such as veterinarians, researchers, zookeepers, wildlife rehabilitation experts, animal control officers, or people traveling to regions where rabies is common. The vaccination can be obtained 
through doctors' offices, travel clinics, and hospitals. Pre-exposure vaccination consists of three shots on days 1,7 , and 21 or 28 . Pre-exposure vaccination eliminates the need for the costly immunoglobulin treatment, but a modified post-exposure treatment is still needed to protect the patient from contracting rabies. If a person does not have pre-exposure vaccination, which is the vast majority of people, then a different course of treatment is required (see next section).

Vaccinations are also available for animals. Rabies vaccination for dogs is mandated by law in all 50 states, and for cats and ferrets in most states, including Florida. The cost is much cheaper, at about $\$ 20$ to $\$ 30$ per shot per year. Wild animals can also be vaccinated, and a large effort is undertaken every year by the Wildlife Services of the US Department of Agriculture's (USDA) Animal and Plant Health Inspection Service to distribute the oral rabies vaccine with the goal of reducing the expansion of raccoon rabies westward. More information, including a map, can be found on the USDA website. Raccoon rabies is the predominant type of rabies found in Florida. The frequency of Florida raccoon-borne rabies over time can be found in Figure 4.

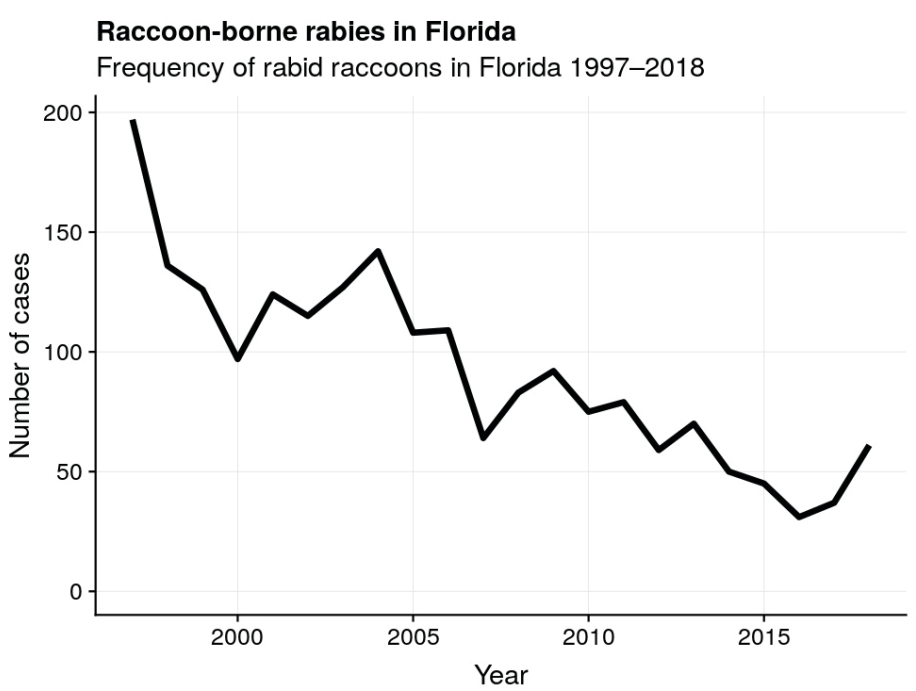

Figure 4. Frequency of raccoon-borne rabies in Florida by year (1997-2018).

\section{POST-EXPOSURE TREATMENT}

Without documentation of current rabies vaccination, treat any mammal bite as a possible rabies exposure case. Do not further endanger yourself trying to collect a potentially rabid raccoon. Instead, inform animal control. A cat or dog may be observed for ten days to identify clinical signs. There is not enough supporting evidence regarding the timeline of viral shedding to prove that observation alone is sufficient for other animals. Unfortunately, the only quick and reliable test involves dissection of the brain, hence euthanasia of the animal is required.

\section{If exposure to rabies is a possibility, it is critical to begin} treatment immediately after the bite or scratch. Because the virus is in the saliva, a rabid animal does not have to bite to transmit rabies: it can transmit the disease by licking broken skin. Wash any wounds immediately. One of the most effective ways to decrease the chance for infection is to wash the wound thoroughly with soap and water. Post-exposure treatment should begin immediately after exposure. Guidelines for post-exposure treatment from the World Health Organization can be found on their website. Post-exposure treatment is available at emergency rooms and county public health offices. The CDC also recommends having a current tetanus vaccination, which must be boosted every 10 years.

Post-exposure treatment consists of four to five shots given at the infection site or in the arm. The shots are administered on days $0,3,7$, and 14 , and, for patients with weakened immune systems, sometimes day 28 . Human rabies immune globulin, made of rabies antibodies, is also administered on day 0 . Anyone who was vaccinated before the exposure receives booster shots on days 0 and 3 , but no immune globulin. Remember, no matter the cost or ordeal of treatment, the alternative is to potentially contract an incurable fatal disease. Post-exposure vaccination has been highly successful in reducing the number of human rabies deaths in the United States from more than 100 per year to just 1 to 2 annually. These cases are typically confined to people who did not know they were exposed to a rabid animal, did not know the risk of handling wildlife, or were bitten by a dog in a foreign country and did not seek treatment. If you suspect that you might have been exposed to a rabid animal, contact your county health department or the Centers for Disease Control; they can help you determine if you were exposed.

More information on rabies can be found in Facts about Wildlife Diseases: Rabies.

\section{Canine Distemper}

Canine Distemper Virus, also known as Canine morbillivirus, is a highly contagious RNA virus in the family Paramyxoviridae. Canine distemper is the leading natural cause of death for raccoons, immediately following human-induced fatalities. Canine distemper virus cannot infect humans, but it can infect and kill many carnivores, including canids, bears, mustelids (weasels, ferrets, skunks, etc.), large felines (not including domestic house cats), 
procyonids (raccoons, kinkajous, ringtails, etc.), and seals. While each group of mammals mentioned is at risk, infection in canids appears to be most common, and is a serious issue for domestic dogs. Vaccination is inexpensive for dogs and is readily available at veterinarians' offices or mobile clinics. The viruses that cause canine distemper and feline distemper (see next section) are not related, and the clinical signs differ. Both viruses can infect raccoons and are very serious diseases.

Symptoms of canine distemper can range from the appearance of an upper respiratory infection (URI) to rabies-like neurological signs. It begins with nasal discharge, fever, conjunctivitis (inflammation and redness of the eye), lethargy, diarrhea, and lack of appetite. As the disease advances, neurological problems may become evident. Dogs have succumbed to infection with signs of a URI or no signs at all. Head tilt, muscle twitching, disorientation, seizures, and deterioration of motor skills can all be seen at later stages. At this point, infection with distemper virus is difficult to differentiate from rabies.

The virus is spread through direct or indirect contact with infected blood, saliva, or urine. While there is no specific cure, symptoms can be alleviated, and the animal can be supported and given the best opportunity to recover using its own immune system. Animals that survive can exhibit lifelong symptoms, ranging from hardened foot pads, to ocular or neurologic signs.

\section{Feline Distemper/Panleukopenia}

Feline Distemper, also known as feline panleukopenia (FP), is a disease caused by the highly contagious feline parvovirus. It is not related to canine distemper, but it is also deadly to raccoons. Feline parvovirus cannot infect humans, but it can infect and kill cats. Bleach can be used as a disinfectant; the virus is resistant to many other chemicals. Vaccination is cheap and readily available at veterinarians' offices and mobile clinics. It is most deadly to kittens and cats with weakened immune systems. Otherwise healthy adult cats have a reasonable chance of survival.

Symptoms include fever, depression, anorexia, dehydration, vomiting, diarrhea, abdominal pain, or sometimes no signs at all. Treatment is supportive and consists of administering fluids, blood or plasma transfusions, and antibiotics for secondary infections.

Feline parvovirus is spread through nasal secretions, blood, feces, urine, or fleas that have been feeding from an infected animal. It can also be spread through poor sanitation of hands, feeding dishes, and other materials. Feline parvovirus attacks rapidly, dividing blood cells in the bone marrow, intestinal epithelium, and lymph nodes. If a cat survives, there are generally no long-term effects.

\section{Canine Parvovirus}

Canine Parvovirus, or parvo, is a highly contagious virus in the family Parvoviridae that causes serious disease in dogs. Raccoons can carry this pathogen with no symptoms, but it can kill unvaccinated dogs. Parvovirus vaccines are inexpensive and are available from veterinarians and mobile clinics.

This virus attacks a dog's gastrointestinal tract. Parvoviruses are highly resistant to heat, cold, and drying and can survive in the environment for long periods of time. Bleach can be used as a disinfectant; the virus is resistant to many other chemicals. It is spread by direct contact with an infected animal, contaminated surfaces, or feces. Signs in dogs include loss of appetite, abdominal pain and bloating, fever, low body temperature, diarrhea, vomiting, and lethargy. Most deaths occur 48 to 72 hours after symptoms are seen.

Treatment is supportive and includes nutritional support, combating dehydration, vomiting, and diarrhea, and treating secondary infections. Even with supportive treatment, the dog may succumb to the infection. This is especially true for puppies.

\section{Bacteria}

\section{Salmonella}

Salmonella is a common cause of food poisoning. Symptoms include vomiting, fever, and diarrhea. These symptoms normally resolve in 3 to 8 days without treatment. However, sometimes severe cases will require antibiotics or hospitalization. Detailed information on Salmonella is available in a series of EDIS documents. Salmonella infection is most often acquired through contaminated food, but can also come from infected mammals, birds, and reptiles through poor sanitation, typically due to fecal-oral transmission. The CDC estimates that Salmonella infects over a million people in the United States each year, causing around 20,000 hospitalizations and 400 deaths. Salmonella can also infect pet mammals and birds and be carried without symptoms by reptiles and amphibians.

\section{Francisella tularensis}

Francisella tularensis causes tularemia, also known as rabbit fever, and can be spread by ticks and contact with 
infected mammalian tissue. Tularemia can be difficult to diagnose in humans and may be mistaken for other diseases. Most people recover, but this can take several weeks of antibiotic treatment. Tularemia is not commonly seen in cats and dogs but when it does infect them, it can cause organ system failure if it is not treated early and aggressively. In order to diagnose tularemia, usually several other diseases must first be ruled out. A vaccine is currently under review. Raccoons have been shown to carry tularemia themselves and by transport of ticks, but it is not clear how tularemia affects raccoons. In humans, exposure can occur through drinking contaminated water, being bitten by an insect carrying the disease, handling animal carcasses, eating undercooked game, or inhaling dried infective animal tissue. Raccoons may be useful as an indicator of tularemia presence in the environment.

\section{Edwardsiella tarda}

Edwardsiella tarda causes Edwardsiella septicemia, a rare but potentially deadly infection in humans and wildlife. However, E. tarda has been found in animals that appear healthy, including raccoons. E. tarda has been found in the intestines of many fish, reptiles, mammals, and birds, and is spread through infected animal feces. Exposure to contaminated water and fish are important factors in transmission. In fact, most reported animal cases have been from species closely associated with water. Edwardsiella septicemia often causes gastroenteritis. Antimicrobial treatment is available, however, a recent literature review found a 44 percent mortality rate in humans even with treatment. Edwardsiella septicemia remains rare, and risk factors are not well understood.

\section{Leptospira}

Leptospira bacteria cause leptospirosis, which may lead to kidney damage, liver failure, meningitis, respiratory distress, and death if left untreated. Virtually all mammals can carry leptospirosis and may or may not show clinical signs. Rodents are thought to be the primary vector. It is spread through contaminated urine and water. Infection is most common in warm and wet areas, but can occur elsewhere. Leptospirosis is seen in dogs, but uncommon in humans in developed countries. Once thought of as a disease of rural areas, reports of leptospirosis infection are on the rise in urban areas, either due to increased prevalence of the disease or increased detection.

\section{Conclusions and Prevention}

With increased development and habitat fragmentation, the risk that humans will come into contact with raccoons and other adaptable species increases. Raccoons readily adapt to urban environments (Figure 5), thus increasing the chance for raccoon-borne diseases to spread to humans and pets. There are a few simple solutions to prevent the spread of raccoon-borne diseases. First, never feed wild animals. In addition to being illegal, feeding wildlife causes animals to associate humans with food, and sometimes to become dependent upon humans. They may lose their natural fear, and they may become aggressive. Feeding wildlife also increases population density and territorial overlap, and the chances of disease transmission between individuals. In addition to not feeding wildlife, feed pets inside, or at least bring food in at night. Purchase raccoon-proof garbage cans if they are getting into your garbage. If you have an unwanted raccoon on your property, call a wildlife removal specialist. The Florida Fish and Wildlife Conservation Commission keeps a list of wildlife removal specialists on their website. Removing a raccoon without professional assistance is difficult and risky, and there is a very high chance the raccoon will come back, or that you remove only part of a family and leave orphans.

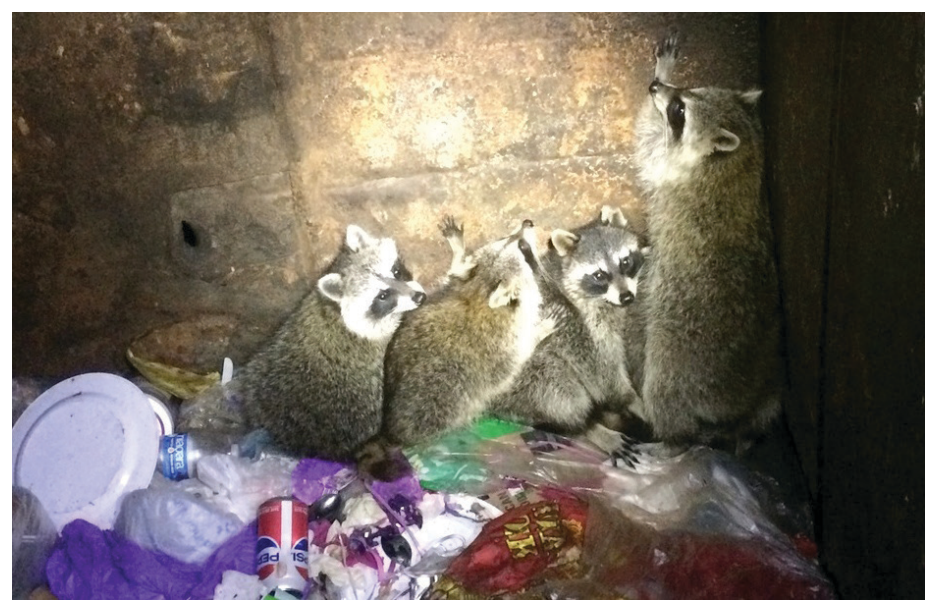

Figure 5. A group (gaze) of five raccoons in a dumpster, a common gathering spot.

Credits: Caitlin Jarvis

The simplest way to protect your pets is to vaccinate them and not let them roam free without supervision. Vaccines to prevent the most common and serious viruses transmitted by raccoons, such as rabies, canine distemper, feline distemper, and canine parvovirus, are relatively inexpensive. For instance, rabies vaccination is available for dogs, cats, and ferrets for around $\$ 20$ to $\$ 30$ per year. Furthermore, in Florida and many other states, it is a legal requirement to have dogs, cats, and ferrets vaccinated against rabies. Adverse reactions are very rare and normally not serious. Full details on legally required preventative treatments can be found in the 2018 Florida Statutes. 
Raccoon-borne diseases pose a significant threat to humans, wildlife, zoo animals, livestock, and pets. With knowledge and simple measures, we can avoid these hazards and be proactive in treatment. Most problems arise when people attract raccoons intentionally or unintentionally. When treated with respect and caution, raccoons can live near humans as an interesting part of the urban ecosystem.

\section{Sources and Further Reading}

Forrester, D. J. 1992. Parasites and Diseases of Wild Mammals in Florida. University Press of Florida, Gainesville. 123-150. http://ufdc.ufl.edu/AA00025659/00001

Kern, W. H. 2018. Northern Raccoon. WEC-34. Gainesville: University of Florida Institute of Food and Agricultural Sciences. https://edis.ifas.ufl.edu/uw033

\section{Rabies}

Mayo Clinic. n.d. "Rabies." Accessed May 14, 2020. https://www.mayoclinic.org/diseases-conditions/rabies/ symptoms-causes/syc-20351821

World Health Organization. 2020. "Rabies." https://www. who.int/en/news-room/fact-sheets/detail/rabies

\section{Canine Distemper}

Creevy, K. E. 2018. "Canine Distemper Overview." Merck Veterinary Manual, Merck \& Co., Inc. https://www.merckvetmanual.com/generalized-conditions/canine-distemper/ overview-of-canine-distemper

\section{Feline Distemper}

Squires, R. A. 2013. "Feline Panleukopenia Overview." Merck Veterinary Manual, Merck \& Co., Inc. https:// www.merckvetmanual.com/generalized-conditions/ feline-panleukopenia/overview-of-feline-panleukopenia

\section{Canine Parvovirus}

American Veterinary Medical Association. 2013. "Canine Parvovirus." https://www.avma.org/resources/pet-owners/ petcare/canine-parvovirus-type-2c-faq

de Cardenas, C. 2008. "Parvo in Dogs." Pet MD. https://www.petmd.com/dog/conditions/ infectious-parasitic/c_dg_canine_parvovirus_infection

\section{Salmonella}

EDIS. n.d. Salmonella. Accessed May 14, 2020. https://edis. ifas.ufl.edu/topic_salmonella

\section{Tularemia}

Williams, K. , and R. Downing. 2019. "Tularemia in Dogs.” VCA Animal Hospitals. https://vcahospitals.com/ know-your-pet/tularemia-in-dogs

\section{Edwardsiella tarda}

Hirai, Y., S. Asahata-Tago, Y. Ainoda, T. Fujita, and K. Kikuchi. 2015. "Edwardsiella tarda Bacteremia. A Rare but Fatal Water- and Foodborne Infection: Review of the Literature and Clinical Cases from a Single Centre." The Canadian Journal of Infectious Diseases \& Medical Microbiology 26:313-318. https://doi.org/10.1155/2015/702615

White, F. H., J. J. Watson, G. L. Hoff, and W. J. Bigler. 1975. "Edwardsiella tarda Infections in Florida Raccoons, Procyon lotor." Archives of Environmental Health: An International Journal 30:601-603. https://doi.org/10.1080/00039896.1975 .10666788

\section{Leptospirosis}

American Veterinary Medical Association. n.d. "Leptospirosis." Accessed May 14, 2020. https://www.avma.org/ public/PetCare/Pages/Leptospirosis.aspx

Centers for Disease Control and Prevention. 2019. "Leptospirosis." https://www.cdc.gov/leptospirosis/index.html

Traxler, R. M., L. S. Callinan, R. C. Holman, C. Steiner, and M. A. Guerra. 2014. "Leptospirosis-Associated Hospitalizations, United States, 1998-2009.” Emerging Infectious Diseases 20:1273-1279. https://dx.doi.org/10.3201/ eid2008.130450 
Table 1. Summary of raccoon-borne viruses and bacteria.

\begin{tabular}{|c|c|c|c|c|}
\hline & Spread & Infect humans or pets? & Prevention & Outcome \\
\hline \multicolumn{5}{|c|}{ Virus } \\
\hline Rabies & Saliva in bites and scratches & $\begin{array}{l}\text { Humans and } \\
\text { mammalian pets }\end{array}$ & Vaccination & Fatal if untreated \\
\hline $\begin{array}{l}\text { Canine } \\
\text { distemper }\end{array}$ & $\begin{array}{l}\text { Direct or indirect contact with } \\
\text { blood, saliva, or urine }\end{array}$ & Ferrets and dogs & Vaccination & $\begin{array}{l}\text { Often fatal; neurological damage } \\
\text { sometimes in survivors }\end{array}$ \\
\hline $\begin{array}{l}\text { Feline } \\
\text { distemper }\end{array}$ & Blood, feces, urine, fleas & Cats & Vaccination & $\begin{array}{l}\text { Fatal in kittens, sometimes fatal in } \\
\text { adults }\end{array}$ \\
\hline $\begin{array}{l}\text { Canine } \\
\text { parvovirus }\end{array}$ & $\begin{array}{l}\text { Direct contact, contaminated } \\
\text { surfaces }\end{array}$ & Dogs & Vaccination & Treatment may prevent fatalities \\
\hline \multicolumn{5}{|c|}{ Bacteria } \\
\hline Salmonella & $\begin{array}{l}\text { Fecal-oral transmission from } \\
\text { contaminated food or animals }\end{array}$ & $\begin{array}{l}\text { Humans, mammalian, } \\
\text { avian, and reptilian pets }\end{array}$ & Sanitation & $\begin{array}{l}\text { Usually resolves without treatment } \\
\text { but may require antibiotics; severe } \\
\text { cases may be fatal }\end{array}$ \\
\hline $\begin{array}{l}\text { Francisella } \\
\text { tularensis }\end{array}$ & Ticks, infected animal tissue & $\begin{array}{l}\text { Humans and } \\
\text { mammalian pets }\end{array}$ & $\begin{array}{l}\text { Tick repellent and removal, } \\
\text { avoid animal tissue }\end{array}$ & $\begin{array}{l}\text { Antibiotics; successful in humans, } \\
\text { less successful in pets }\end{array}$ \\
\hline $\begin{array}{l}\text { Edwardsiella } \\
\text { tarda }\end{array}$ & Contaminated water and fish & $\begin{array}{l}\text { Rare in humans, could } \\
\text { infect pet mammals, } \\
\text { amphibians, and reptiles }\end{array}$ & $\begin{array}{l}\text { Avoid contaminated water } \\
\text { and fish }\end{array}$ & Treatable, but can be fatal \\
\hline Leptospira & Contaminated urine and water & $\begin{array}{l}\text { More common in dogs, } \\
\text { seen in humans and cats }\end{array}$ & $\begin{array}{l}\text { Sanitation; avoid } \\
\text { contaminated water }\end{array}$ & Can be fatal, can show no signs \\
\hline
\end{tabular}

Table 2. Reported rabies cases in raccoons in Florida from 1997-2018 by county (data from the Florida Department of Health).

\begin{tabular}{|c|c|c|c|c|c|c|c|}
\hline County & Total & County & Total & County & Total & County & Total \\
\hline Alachua & 105 & Flagler & 11 & Lake & 63 & Pinellas & 30 \\
\hline Baker & 1 & Franklin & 3 & Lee & 32 & Polk & 126 \\
\hline Bay & 70 & Gadsden & 1 & Leon & 71 & Putnam & 21 \\
\hline Bradford & 2 & Gilchrist & 9 & Levy & 13 & St. Johns & 20 \\
\hline Brevard & 51 & Glades & 1 & Liberty & 2 & St. Lucie & 24 \\
\hline Broward & 31 & Gulf & 6 & Madison & 3 & Santa Rosa & 15 \\
\hline Calhoun & 8 & Hamilton & 19 & Manatee & 18 & Sarasota & 46 \\
\hline Charlotte & 13 & Hardee & 10 & Marion & 171 & Seminole & 90 \\
\hline Citrus & 39 & Hendry & 7 & Martin & 31 & Sumter & 8 \\
\hline Clay & 20 & Hernando & 35 & Monroe & 5 & Suwannee & 29 \\
\hline Collier & 12 & Highlands & 12 & Nassau & 16 & Taylor & 0 \\
\hline Columbia & 20 & Hillsborough & 79 & Okaloosa & 12 & Union & 7 \\
\hline Dade & 13 & Holmes & 15 & Okeechobee & 3 & Volusia & 84 \\
\hline DeSoto & 1 & Indian River & 19 & Orange & 106 & Wakulla & 1 \\
\hline Dixie & 10 & Jackson & 50 & Osceola & 24 & Walton & 12 \\
\hline Duval & 37 & Jefferson & 2 & Palm Beach & 147 & Washington & 6 \\
\hline Escambia & 13 & Lafayette & 3 & Pasco & 63 & Florida Total & 2027 \\
\hline
\end{tabular}


